\title{
Prospective survey to verify the Ottawa ankle rules
}

\author{
Samantha Perry, Nigel Raby, Patrick T Grant
}

\begin{abstract}
Objective-To determine if the Ottawa ankle rules are valid in the setting of an urban teaching hospital in the UK.

Design-A prospective survey. Setting-Accident and emergency department, Western Infirmary, Glasgow from 1 April 1995 to 31 August 1995.

Subjects -800 patients with an acute ankle injury.

Results-800 patients were used for analysis of which $584(73 \%)$ were radiographed; $70(12 \%)$ had fractures, $63(10.8 \%)$ of which were significant. Four of these patients with fractures fulfilled none of the Ottawa ankle rules criteria for plain radiography.

Conclusion-Application of the Ottawa ankle rules to this group of patients would have produced a sensitivity of $93.6 \%$. Although useful, decision rules should be used with care and not replace clinical judgment and experience.
\end{abstract}

$(\Im$ Accid Emerg Med 1999;16:258-260)

Keywords: Ottawa ankle rules; ankle fractures

Ankle injuries are one of the most common problems presenting to an accident and emergency (A\&E) department. Most patients are referred for radiography but it is estimated that only $15 \%$ will have a fracture. ${ }^{1}$ Several authors have reviewed the use of radiography in patients with ankle injuries and have come to differing conclusions. Some have suggested that it is not possible to safely reduce the number of radiographs, ${ }^{2}$ while others have attempted to develop clinical guidelines that could identify those patients requiring radiography ${ }^{3}$; however, none of these has been widely accepted into clinical practice. More recently, Stiell and colleagues derived a set of guidelines, which have gained some acceptance and are commonly referred to as the Ottawa ankle rules. ${ }^{4}$ Their initial study involved 750 patients in which 32 clinical variables were analysed for their reliability to predict the presence of a fracture. The Ottawa ankle rules state that radiography is only necessary if, after trauma, there is pain near the malleoli and one or more of the following findings are present: (A) the patient is $>55$ years or, (B) the patient is unable to weight bear immediately after the injury and unable to take four steps in the $A \& E$ department or, (C) there is evidence of bony tenderness at the posterior edge or tip of either malleolus. ${ }^{4}$

The original authors in two subsequent studies validated these rules. ${ }^{56}$ If the rules are correctly applied it is claimed that ankle radiography could be reduced by a third and the rate of significant missed fractures not increased. The aim of this study was to determine if such rules were valid in the setting of an urban teaching hospital in the UK.

\section{Method}

Data were collected from patients presenting to our $A \& E$ department with ankle injuries over a period of five months from 1 April 1995 until 31 August 1995. The department has a catchment area of 250000 of mixed socioeconomic groups. In 1995, 59608 new patients were seen. Staffing comprised two consultants, one senior registrar, one specialist registrar, two senior senior house officers, six senior house officers, and a number of clinical assistants of varied backgrounds. Patients who were under the age of 18, intoxicated with alcohol or drugs, had sustained multiple injuries, or transferred from other hospitals were excluded.

The patients were thus seen by a variety of doctors, none of whom had received any formal teaching within the department with respect to the Ottawa ankle rules. However, it was accepted that some of the doctors may have had knowledge of the rules from their own reading.

After clinical assessment, data were recorded in a standard format by way of a stamper in the $A \& E$ record card (table 1). Apart from the authors, all the doctors working in the $A \& E$ department were blinded to the study. They were simply asked to use the stamper for every patient whom they managed with an ankle injury and not to change their usual clinical practice. Twelve parameters were recorded only four of which-age, posterior malleolar tenderness, inability to weight bear immediately, and weight bear in the $A \& E$ department-were required for the study. None of the doctors was informed of the study or which specific parameters were being analysed.

Patients were identified from a coded computer register of all A\&E attendances. Any patient thought to require radiographic examination at the discretion of the examining

Table 1 Ankle injury stamper data: answer "yes" or "no"

Fall from a height

Inversion injury

Bruising

Swelling

Inability to weight bear (immediately)

Inability to weight bear (in department)

Age $>55$

Bony tenderness anterior edge of malleolus

Bony tenderness posterior edge of malleolus

Pain

Limitation of dorsiflexion

General practitioner request

Patient request

Other (please specify) 


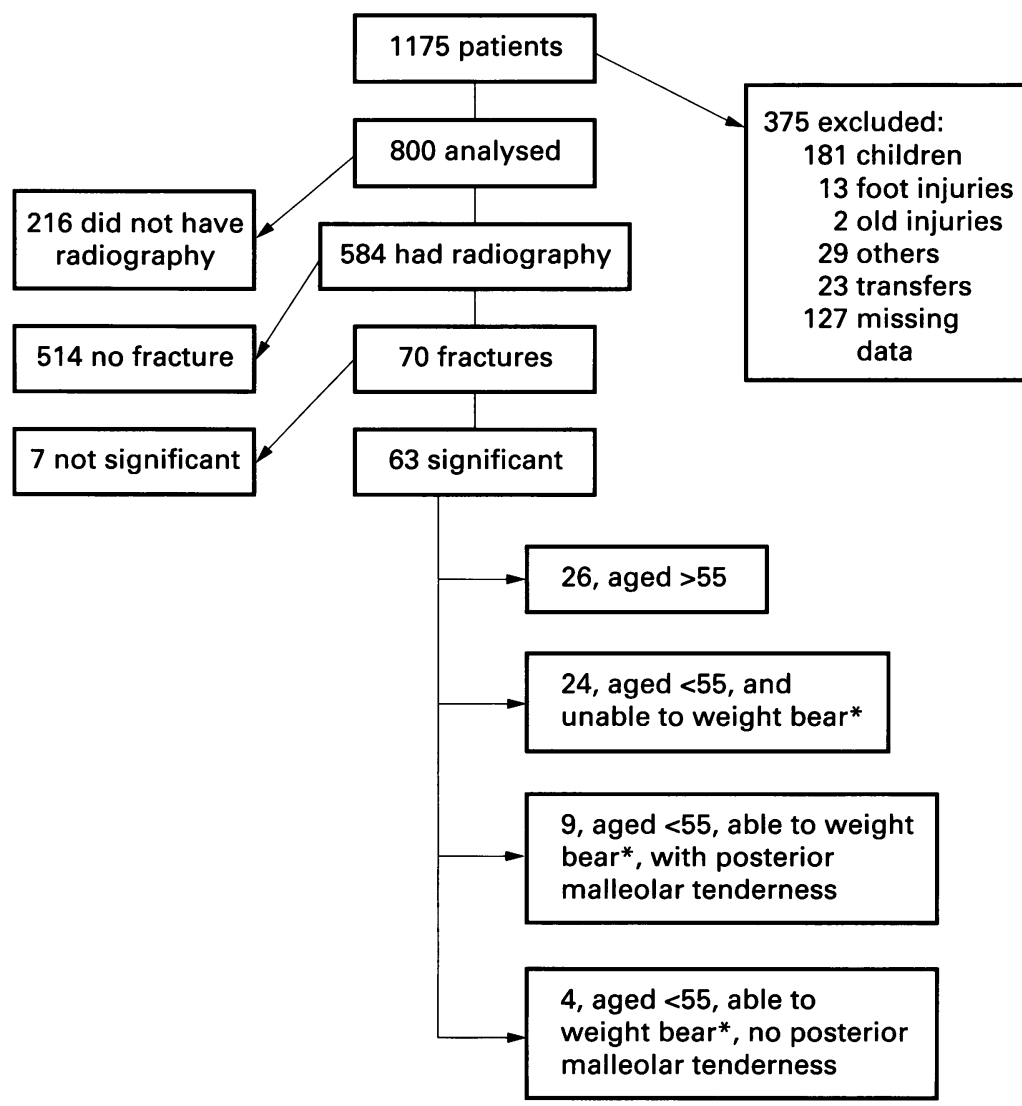

Figure 1 Summary of all patients; *ability to weight bear immediately and take four steps in the $A \mathcal{E} E$ department.
Table 3 Details of patients not fulfilling Ottawa ankle rules for plain radiography

\begin{tabular}{lll}
\hline Patient & Age (years) & Site of ankle fracture \\
\hline 1 & 20 & Posterior malleolar fracture \\
2 & 33 & Lateral malleolar fracture \\
3 & 50 & Bimalleolar fracture \\
4 & 54 & Lateral malleolar fracture \\
\hline
\end{tabular}

giving a sensitivity of $93.6 \%$, and specificity of $46 \%$ (table 3 ). The positive predictive value was $17.98 \%$ and negative predictive value $98.39 \%$. Of the 514 patients whose radiographs were negative, $269(52 \%)$ had one or more indications for radiography. Analysis of the 215 patients who were not radiographed revealed that $41(19 \%)$ had one or more indication for radiography. None of these patients were known to have returned to this A\&E department during the study period.

The case records of those patients with significant fractures but who would not have had radiography had the rules been applied were reviewed retrospectively. Appropriate documentation had been completed and there were no apparent reasons to explain why the rules did not identify the four patients in this category.

\section{Discussion}

The Ottawa ankle rules have previously been verified by the original authors in a multicentre trial involving eight Canadian hospitals. ${ }^{6}$ The rules were introduced by means of a one hour lecture, a hand out, pocket cards, and posters. During a six month period, Stiell and colleagues collected data on 6489 patients. Compared with the previous 12 months, before the introduction of the rules, there was an approximate $20 \%$ reduction in the use of ankle radiography. Of their 1082 significant fractures, five $(0.46 \%)$ patients had ankle fractures diagnosed in which the rules were interpreted as negative. Review of these cases indicated that either there was gross swelling preventing adequate examination for bony tenderness or the rules had been misinterpreted. Nine of their patients had a fracture diagnosed subsequently after discharge, because either the radiograph had been misread or the rules were retrospectively found to have been misinterpreted.

Our study has shown that if the Ottawa ankle rules had been applied in our department there may have been a $30 \%$ reduction in radiography rate during that time period with associated cost benefit. However, four out of 63 (6.3\%) significant ankle fractures would have been missed, a much higher percentage than that found in the study of Stiell et al. ${ }^{45}$

The impact of such missed fractures is difficult to quantify but is likely to result in increased morbidity for the patient and may have medicolegal consequences. Review of the case notes of these patients did not provide any explanation as to why the rules were interpreted as negative. It is possible that the examining doctor may have incorrectly recorded his/ her findings. Data about malleolar tip tenderness were not recorded on our stamper, which could have underestimated the number 
of patients who were "Ottawa positive" and, therefore, may have picked up a "potentially missed fracture" had the rules been applied. Of those patients discharged without receiving radiography, it is not known how many, if any, presented to another department in the city, or elsewhere, and were subsequently found to have a fracture.

Our study had other limitations. From a scientific point of view it could be argued that the most appropriate course of action would have been to take radiographs of the whole study group leaving no unanswered questions about the 41 patients who were "Ottawa positive" but not radiographed. Similarly it is entirely possible that some patients who were Ottawa negative and did not have radiographs taken could have undiagnosed fractures. This issue was considered when devising the study but we felt that it was unethical to expose a significant number of patients to unnecessary radiation. We, therefore, simply advised doctors to continue with their usual practice. Published evidence on this topic is conflicting. A number of researchers have highlighted the usefulness of the Ottawa ankle rules $^{78}$ and, indeed, one recent study from the UK stated that they could be safely applied by appropriately trained nursing staff; however their radiography rate was $73 \%$ (as in our study) perhaps suggesting a more liberal interpretation of the rules.' By contrast, other studies have been unable to validate the rules in a local setting. ${ }^{10} 11$

Although our study involved a smaller number of patients to that of Stiell, it does draw attention to the potential dangers of rigidly adhering to decision rules. It is interesting to note the much higher fracture rate in Stiell's study in comparison to our own (1082/ $6489,16.7 \%$ v 63/800,7.9\%). This suggests that the two patient groups may be different, perhaps with a larger number of our patients attending with more "trivial" injuries, than in
Canada, questioning, therefore, the direct application of decision rules that have been developed in a different population base.

Our study provides additional supporting evidence that clinical decision rules are not infallible. It is our contention that while such rules may be useful, they must always be tempered by clinical judgment and experience. A\&E departments should be cautious about the rigid application of the Ottawa ankle rules and junior doctors should be encouraged to exercise careful clinical judgment and seek more senior advice where necessary.

We would like to thank the medical staff of the A\&E department for recording the relevant data and Miss L Russell for typing the manuscript.

Conflict of interest: none.

Funding: none.

1 Brooks SC, Potter BT, Rainey JB. Inversion injuries of the ankle: the clinical assessment and radiographic review. $B M F$ 1981;282:607-8.

2 Charny M C, Ennis W P, Roberts C J, et al. Can the use of radiography of arms and legs in accident and emergency units be made more efficient? BMF 1987;294:291-3.

3 Dunlop MG, Beattie TF, White GK, et al. Guidelines for selective radiological assessment of inversion ankle injuries. $B M \mathcal{A}$ 1986;293:603-5.

4 Stiell IG, Greenberg GH, McKnight RD, et al. A study to develop clinical decision rules for the use of radiography in acute ankle injuries. Ann Emerg Med 1992;21:384-90.

5 Stiell IG, Greenberg GH, McKnight RD, et al. Decision rules for the use of radiography in acute ankle injuires. Refinement and prospective validation. $¥ A M A 1993 ; 269$ : 1127-32.

6 Stiell I, Wells G, Laupacis A, et al. Multicentre trial to introduce the Ottawa ankle rules for use of radiography in acute ankle injuries. $B M \mathcal{F} 1995 ; 311: 594-7$.

7 Verma S, Hamilton K, Hawkins $\mathrm{HH}$, et al. Clinical application of the Ottawa ankle rules for the use of radiography in acute ankle injuries: an independent site assessment. $A m \mathcal{F}$ Radiol 1997;169:825-7.

8 Auleley GR, Kerboull L, Durieux P, et al. Validation of the Ottawa ankle rules in France: a study in the surgical emergency department of a teaching hospital. Ann Emerg Med 1998;32:14-18.

9 Salt P, Clancy M. Implementation of the Ottawa ankle rules by nurses working in an accident and emergency department. $\mathcal{f}$ Accid Emerg Med 1997;14:363-5.

10 Kelly AM, Richards D, Kerr L, et al. Failed validation of a clinical decision rule for the use of radiography in acute clinical decision rule for the use of radiogr.
ankle injury. $N Z M$ Med $¥ 1994 ; 107: 294-5$.

11 Lucchesi GM, Jackson RE, Peacock WF, et al. Sensitivity of the Ottawa rules. Ann Emerg Med 1996;27:103-4. 